\title{
Numerical Study of Heterogeneous Reactions in an SOFC Anode With Oxygen Addition
}

\author{
Yong Hao, David G. Goodwin \\ Division of Engineering and Applied Science, California Institute of Technology, \\ Pasadena, CA 91125, USA
}

\begin{abstract}
Previous experimental studies have shown that addition of small amounts of oxygen to a hydrocarbon fuel stream can control coking in the anode, while relatively large amounts of oxygen are present in the fuel stream in single-chamber SOFCs. In order to rationally design an anode for such use, it is important to understand the coupled catalytic oxidation / reforming chemistry and diffusion within the anode under SOFC operating conditions. In this study, the heterogeneous catalytic reactions in the anode of an anode-supported SOFC running on methane fuel with added oxygen are numerically investigated, using a model that accounts for catalytic chemistry, porous media transport, and electrochemistry at the anode/electrolyte interface. Using an experimentally validated heterogeneous reaction mechanism for methane partial oxidation and reforming on nickel, we identify three distinct reaction zones at different depths within the anode: a thin outer layer in which oxygen is nearly fully consumed in oxidizing methane and hydrogen, followed by a reforming region, then a water-gas shift region deep within the anode. Based on these insights into the chemistry, the possibility of a composite anode with different layers of metal catalysts is also explored for the improvement of fuel cell performance.
\end{abstract}

\section{Introduction}

Among the components of an SOFC, the anode presents perhaps the most significant technical barriers to creating an efficient, economic and environment-friendly technology that makes better use of readily available fuels (1). Ongoing research has been trying to address these issues by seeking anode materials that possess excellent catalytic, electrochemical and mechanical properties, and the nickel-zirconia cermet anodes is currently the dominant SOFC anode due to their structural stability, small thermal expansion mismatch with popular electrolyte materials, and good catalysis to hydrogen oxidation and steam reforming of hydrocarbon fuels (1). In particular, the anodesupported MEA (membrane-electrolyte assembly) structure is advantageous for hydrocarbon fuels, for it also serves as a reforming or catalytic partial oxidation (CPOX) catalyst in addition to conducting current (2). However, it is generally not possible to operate nickel-based anodes on higher hydrocarbon-containing fuels because nickel also catalyses the formation of carbon filaments (i.e. coking) from hydrocarbons under reducing condition (1), and coking can still occur on $\mathrm{Ni}$ catalysts even under thermodynamically non-coking conditions (3). Formation of carbon deposits on $\mathrm{Ni}$ particles is responsible for excessively high activation polarization, which leads to the rapid deterioration of cell performance (4). For example, Zhan et al. reported that the use of iso-octane causes severe coke buildup on the Ni-YSZ anode and leads to degradation 
of the anode (3). Various approaches including steam reforming, addition of oxygen to the fuel stream, and incorporation of dopants into the conventional anode material have been tried to mitigate this problem $(1,2)$.

The oxygen addition approach is the focus of this paper. For the purpose of carbon removal, it has the advantage (compared with steam reforming) of working well for both methane and higher hydrocarbons, and only a small amount is needed, without substantially affecting the cell efficiency $(1,3)$. For example, Zhan et al. report that a $2 \%$ addition to the iso-octane fuel yielded fully stable performance without measurable carbon deposits (3). While effective for suppressing coke formation for SOFCs in general, mixing oxygen with hydrocarbon fuels (and the ensuing catalytic reactions) in particular is also the working principle of single-chamber SOFCs (SCFC). More than just the reactant for cathode electrochemistry, oxygen can react with the fuel on the anode side as well, generating hydrogen for anode electrochemistry. Ni-based catalysts have been demonstrated to also exhibit a good activity and selectivity for synthesis gas formation from $\mathrm{CH}_{4} / \mathrm{O}_{2}$ mixtures (5). Also, the oxidation of the fuel is exothermic, which can help mitigate the cooling effect of the endothermic reforming reaction in the anode bulk, and in some cases can help maintain the operating temperature (3). Especially in the presence of a large amount of oxygen (as in the case of SCFCs), the heat release becomes so intense that a substantial temperature rise is usually observed experimentally, which in some cases, can allow the fuel cell to work steadily without additional external heating (e.g. a furnace) (6).

Despite the possible benefits of oxygen addition, current understanding of the detailed reaction mechanism of oxygen with the fuel species in a typical SOFC anode is rather limited due to the complexity of the reactions, the lack of experimental diagnostic methods that could resolve the reactions in the microstructure in-situ, and the current focus on steam reforming in numerical modeling studies.

In this paper, the heterogeneous reactions in the anode of an anode-supported MEA with both large (for SCFC) and small (for dual-chamber SOFC) oxygen addition are studied numerically using the numerical model we have described previously (7) for a methane-fueled SOFC. Although the oxidation of the fuel in general could occur both in the gas-phase (i.e. homogeneous) and between the gas-phase and the catalyst surface (i.e. heterogeneous) (2), for methane the homogeneous reaction does not play a substantial role for SOFCs until $900^{\circ} \mathrm{C}(8)$, which is higher than the normal operating temperature of most SOFCs. Therefore, in this paper we consider heterogeneous chemistry only.

In the existing literature concerning using oxygen for coke prevention in SOFC operation, the role of oxygen in the heterogeneous reactions is not clear (3), and in the majority of the SCFC studies, its role is vaguely explained as partially oxidizing the hydrocarbon fuel to produce syngas, without any discussion of the reaction pathway (9). It is a common practice to use mass spectrometer $(3,10)$ or gas chromatograph $(11)$ to analyze the outlet gas in an SOFC experiment, which is necessary but far from being sufficient to determine what reactions are actually taking place in the anode.

Studies using fixed-bed reactors provide some useful insights. DeGroote et al. shows the existence of total combustion followed by steam reforming reactions and water-gas shift reaction in a numerical study of catalytic partial oxidation of methane to syngas over 
nickel (12). Deutschmann et al. carried out a series of experimental and modeling studies concerning surface and gas-phase chemistry on different catalyst metals in a shortcontact-time reactor $(5,13)$. From these measurements, they developed a multi-step, elementary reaction mechanism to describe steam-assisted catalytic partial oxidation of methane in small-channel monolith reactors using Ni supported on alumina. This paper employs the mechanism developed by Deutschmann et al. in (14) to study the anode catalytic chemistry with various oxygen additions under typical SOFC operating conditions. The reliability of the mechanism has been validated by the work of Hecht et al. for dual-chamber SOFC (15) and our previous work for single-chamber SOFC (16) for cases with and without oxygen addition in the fuel stream. For the purposes of this study, we will assume this reaction mechanism provides an adequate description of the catalytic chemistry within an SOFC anode. We will show that the reactions in the anode are much more complex than a simple, distributed partial oxidation, and that understanding these reactions (including combustion, reforming and shift reactions) will be helpful to optimize the anode structure. The numerical model used for this paper was originally developed for single-chamber SOFCs, but with the experimental validation of the simulation results (16), useful conclusions could be drawn for dual-chamber cases as well. However, this mechanism was not designed to predict coking, and so in this study, we only discuss cases for which coking is not a problem.

\section{Numerical Model}

The two-dimensional model used in this study was originally developed for SCFCs running on hydrocarbon fuels, and is described in more detail in Ref. (7). By fitting a small number of parameters, good agreement was achieved between the model's prediction and other independent experimental results. The model describes gas flow and species transport, heat transfer in the gas phase, multi-component species transport in porous electrodes, and catalytic partial oxidation and reforming chemistry at the anode, and incorporates a Butler-Volmer formalism for electrode kinetics. It is capable of handling both pure ionic and mixed ionic-electronic conductor electrolytes.

One of the strengths of this model is that, given a heterogeneous reaction mechanism, not only the distribution of gas-phase and surface-phase species within the porous electrodes can be obtained, but the reaction rates of each species and the heat release rates at every point within the electrode can be calculated. Furthermore, surface reactions can be turned on or off depending on the needs of the study. These features are very useful in studying the catalytic kinetics within the anode with oxygen addition in the fuel stream.

However, we have to point out that among the basic assumptions of the model (7), treating the electrochemistry as a boundary condition for the electrode is a great simplification, for it is well known that electrochemically active region extends at least ten microns into the porous electrode (17). For thin electrodes (e.g. a few tens of microns), this is going to be an oversimplification, because electrochemistry over the triple-phase boundary (TPB) will affect the surface chemistry over a significant portion of the electrode thickness. But for this study, the assumption will not make a major difference in the conclusions, because the anode in an anode-supported MEA is usually around $1 \mathrm{~mm}$ thick. 
In keeping with our previous work (16), the anode and cathode of cells studied in this paper are nickel/YSZ and $\mathrm{Ba}_{0.5} \mathrm{Sr}_{0.5} \mathrm{Co}_{0.8} \mathrm{Fe}_{0.2} \mathrm{O}_{3}(\mathrm{BSCF})$, respectively. The electrolyte is either YSZ or $\mathrm{Ce}_{0.8} \mathrm{Sm}_{0.2} \mathrm{O}_{1.9}$ (SDC). The thicknesses of the anode, cathode and electrolyte are taken to be 700,10 and $15 \mu \mathrm{m}$, respectively, and temperature is fixed at $750{ }^{\circ} \mathrm{C}$, unless stated otherwise. The cell runs in a mixture of methane and oxygen with specified flow rates, with helium being the balance gas. The flow rate of methane is 87 $\mathrm{sccm}(\mathrm{ml} / \mathrm{min}$ at standard conditions) and the ratio of oxygen to helium is always 1:4. The dimensions of the gas channel are $15.875 \mathrm{~mm}$ by $142.875 \mathrm{~mm}$ and other details of the computational domain can be found in Ref. (16).

\section{Results and Discussion}

We start with a YSZ cell in the single-chamber configuration at open-circuit condition. Compared with SDC electrolytes, YSZ is a pure ionic conductor and the rate of electrochemisty at electrode-electrolyte interfaces at all locations along the cell approaches zero under such a condition, thus simplifying the study for the anode reactions by ruling out the influence of electrochemistry. For this case, we set the fuel-tooxygen ratio at the inlet to be the partial oxidation stoichiometry, i.e. $\mathrm{CH}_{4}: \mathrm{O}_{2}: \mathrm{He}=2: 1: 4$. The computational grid for the anode is automatically refined by the model, and the finest grid sizes, which occur at the anode-gas and anode-electrolyte interfaces, are around $1 \mu \mathrm{m}$, enough for resolving the species profiles. The cell is divided into 7 segments of equal lengths along the flow direction, and the central one, which is about $6.7 \mathrm{~mm}$ from the fuel cell leading edge, is chosen for analyzing the results.

Figure 1 (a) shows the concentration of gas-phase species within the anode. Although the amount of oxygen is half that of methane at the inlet, it is much less over the anodegas interface due to the catalytic reactions in the anode that we will discuss shortly. It is also obvious that oxygen penetrates into the anode only about $25 \mu \mathrm{m}$, while methane is abundant throughout the whole anode thickness. The quick depletion of $\mathrm{O}_{2}$ and the production of $\mathrm{H}_{2} \mathrm{O}$ and $\mathrm{CO}_{2}$ near the anode-gas interface indicate the possibility of combustion instead of partial oxidation or reforming reactions.

A further study of the surface reaction rates reveals a three-layer structure of the anode reactions and confirms the existence of a combustion zone, shown in Fig. 1 (b). All the rates are normalized by that of methane. That is, the production rate of methane is always
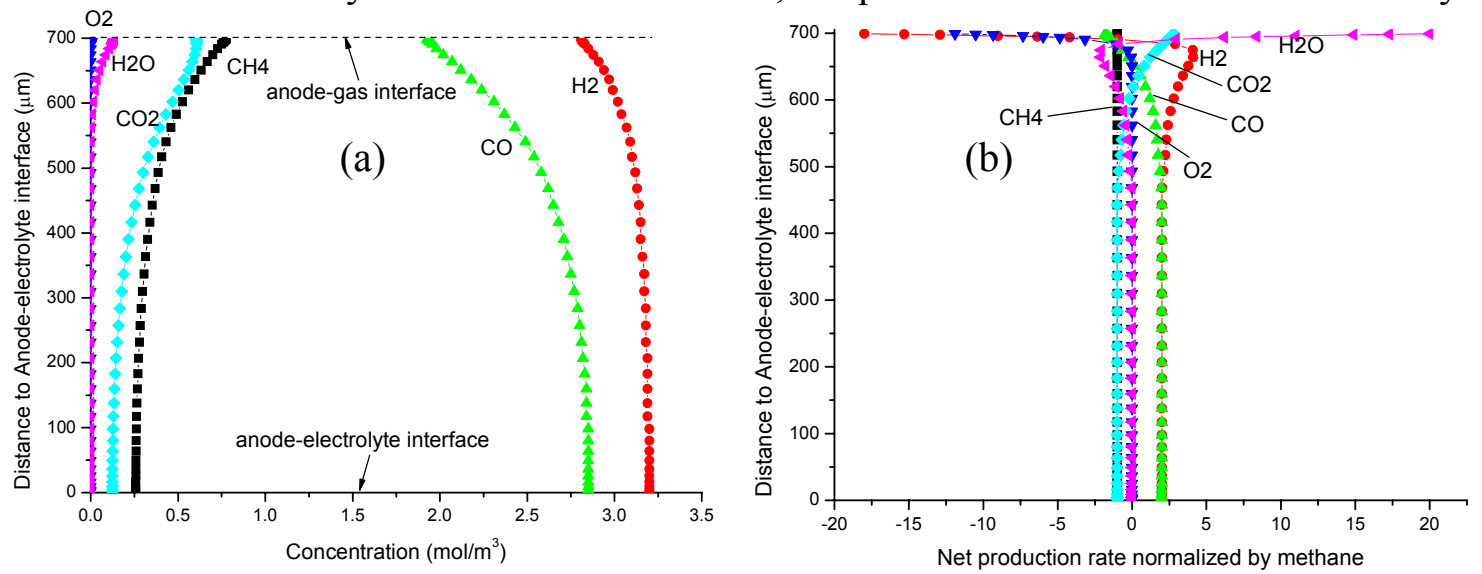

Figure 1. Concentration and net production rates of gas species in the anode at opencircuit condition 
-1 (minus sign means "consumed"), and the rate for any other species means how many moles of such species is produced for each mole of methane consumed. Starting from the anode-gas interface, $99 \%$ of the $\mathrm{O}_{2}$ is consumed within a $25 \mu \mathrm{m}$-thick layer by combustion with $\mathrm{H}_{2}$ and $\mathrm{CO}$ produced deeper in the anode, rather than $\mathrm{CH}_{4}$. At $1 \mu \mathrm{m}$ beneath the interface, for example, the global reaction can be written as $\mathrm{CH}_{4}+18 \mathrm{H}_{2}+$ $1.8 \mathrm{CO}+11.9 \mathrm{O}_{2}=2.8 \mathrm{CO}_{2}+20 \mathrm{H}_{2} \mathrm{O}$, and understandably the reaction in this layer is highly exothermic. The heat release of the fuel cell is concentrated in this thin layer and transferred to the other parts through conduction. The methane partial oxidation claimed in literature is unlikely to occur because nickel is an excellent catalyst for the oxidation of hydrogen (1), and in the presence of a large amount of syngas (as reported in literature), it is impossible for $\mathrm{O}_{2}$ to selectively react with $\mathrm{CH}_{4}$ but not with either $\mathrm{H}_{2}$ or $\mathrm{CO}$.

The syngas consumed in the combustion zone is generated by the reforming zone extending roughly from 25 to $200 \mu \mathrm{m}$ away from the anode-gas interface, into which the $\mathrm{H}_{2} \mathrm{O}$ produced in the combustion layer diffuses and reacts with methane. $\mathrm{H}_{2} \mathrm{O}$ is depleted in this layer, and in the third layer that immediately follows, which extends up to $500 \mu \mathrm{m}$ above the anode-electrolyte interface, the syngas is produced by methane and $\mathrm{CO}_{2}$ from the combustion layer, and the global reaction can be written as $\mathrm{CH}_{4}+\mathrm{CO}_{2}=2 \mathrm{CO}+2 \mathrm{H}_{2}$.

The three-layer structure of the anode is in general agreement with the indirect route of the syngas production suggested by Ishihara et al. (5) in the study of methane partial oxidation with oxygen permeating ceramic membrane reactors, for which combustion of $\mathrm{CH}_{4}$ to $\mathrm{CO}_{2}$ and $\mathrm{H}_{2} \mathrm{O}$ is followed by reforming reaction of $\mathrm{CH}_{4}$ with $\mathrm{H}_{2} \mathrm{O}$ and $\mathrm{CO}_{2}-\mathrm{CO}$ and water-gas shift conversions. The $25 \mu \mathrm{m}$-thick combustion layer mimics the reactor entrance, where an extremely rapid variation of temperature, velocity, and transport coefficients occurs (5). The heat release in this layer not only provides the heat for the endothermic steam reformation (2), but also leads to a significant temperature rise, verified both experimentally by several groups $(6,18,19,20)$ and numerically by our previous work (16).
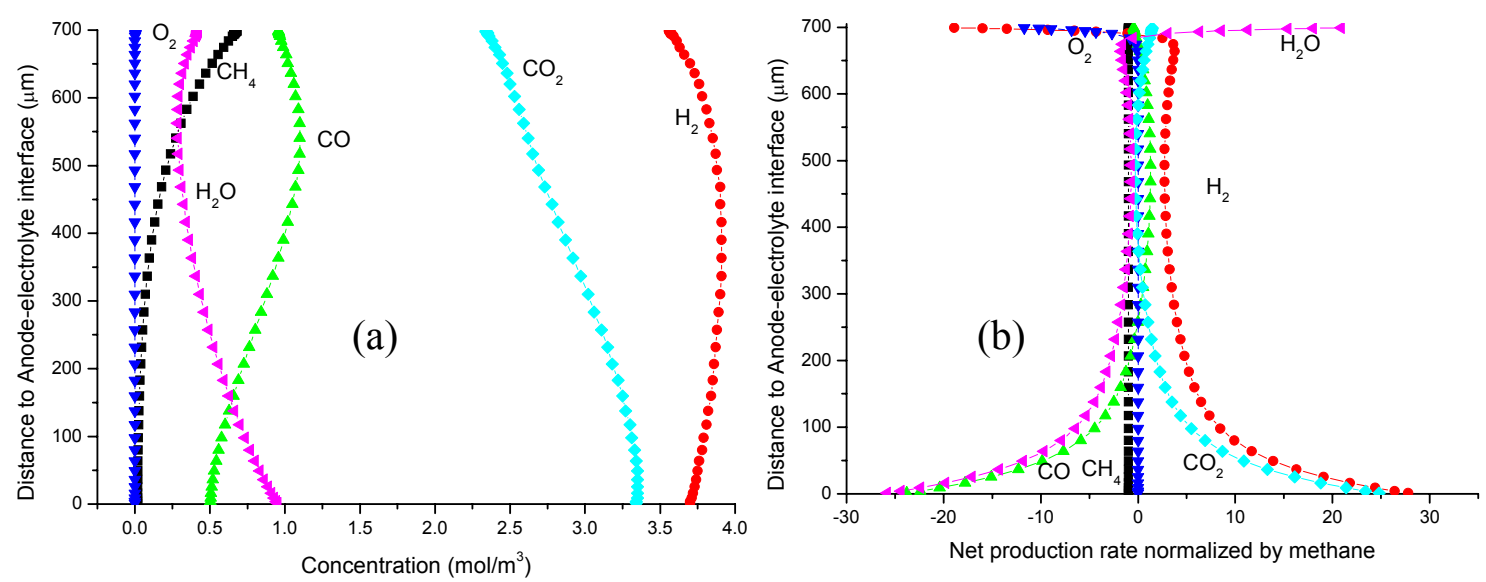

Figure 2. Concentration and net production rates of gas species in the anode at $0.5 \mathrm{~V}$.

However, one major difference between the reactor and an SOFC anode is the contribution of steam by electrochemistry. Because $\mathrm{H}_{2} \mathrm{O}$ plays an important role in both reforming and water-gas shift reactions, the layered structure of the anode in the presence of electrochemical reactions can be different and needs a further study. Therefore we 
change the load potential to $0.5 \mathrm{~V}$ (for maximum power output) and the results are shown in Fig. 2. By comparison, a large amount of $\mathrm{H}_{2} \mathrm{O}$ is produced by electrochemistry, providing enough steam for the reforming of methane and the water-gas shift reactions. As a result, the concentration of methane decays more rapidly with depth into the anode, and the concentrations of hydrogen and $\mathrm{CO}_{2}$ are higher while that of $\mathrm{CO}$ is considerably lower compared with the open-circuit case. The similarities include the combustion layer of $\sim 25 \mu \mathrm{m}$ thick and the reforming layer, with thickness extends from 175 to $475 \mu \mathrm{m}$ due to the higher concentration of $\mathrm{H}_{2} \mathrm{O}$. As for the third layer, not only the thickness reduces to $\sim 200 \mu \mathrm{m}$, but instead the dominant reaction is water-gas shift, also due to the presence of $\mathrm{H}_{2} \mathrm{O}$.

In Fig. 2, it is interesting to notice that there are a minimum for $\mathrm{H}_{2} \mathrm{O}$ at $\sim 600 \mu \mathrm{m}$ and a maximum for $\mathrm{H}_{2}$ at $\sim 400 \mu \mathrm{m}$. A calculation of mass fluxes of species shows that the steam produced by the combustion layer never goes downwards beyond the $600 \mu \mathrm{m}$ line, and the $\mathrm{H}_{2}$ and $\mathrm{CO}$ generated by this part of the steam diffuses back to be fully oxidized. On the other hand, the steam generated by electrochemistry goes upwards to the $600 \mu \mathrm{m}$ line. The $\mathrm{H}_{2}$ it generates through reforming partly diffuses to the combustion layer, and partly diffuses back to the anode-electrolyte interface, where it is converted to $\mathrm{H}_{2} \mathrm{O}$ again. This means that the $\mathrm{H}_{2}$ for electrochemistry is not directly relevant to the oxidation of methane, but is solely produced by internal reforming. The major role of $\mathrm{O}_{2}$ is supplying the heat to steam reforming by way of full oxidation of the syngas. The combustion makes the gas mixture in the flow channel increasingly fuel-rich so that more oxygen is needed by the downstream part of the fuel cell, shifting the optimum fuel-to-oxygen ratio towards the fuel-lean condition (7). For this reason, neither can the working principle of SCFC be simply explained as the partial oxidation of methane, nor does it make sense to superpose the local reactions to get some nominal "global" reaction for the whole anode, because different regions of the anode are responsible for different functionalities.

The three-layered structure of the anode exists for a wide range of operation parameters including voltage ( 0 volt to open-circuit), temperature $\left(550^{\circ} \mathrm{C}-800^{\circ} \mathrm{C}\right.$ at least) and the fuel-to-oxygen ratio ( 0.5 to 2.0 at least), and the general pattern is the same. However, there are quantitative differences depending on specific conditions. For example, at lower voltages (e.g. short-circuit), methane is depleted faster due to the higher concentration of $\mathrm{H}_{2} \mathrm{O}$ produced by electrochemistry, and therefore the reforming layer is narrower, while the water-gas shift layer is wider; at smaller fuel-to-oxygen ratios (e.g. stoichiometry for methane combustion), the combustion layer can be much wider due to the abundant oxygen, resulting in a very low $\mathrm{H}_{2}$ concentration and power output. As for temperature, although the Deutschmann mechanism does not apply above $800^{\circ} \mathrm{C}$, it can be inferred that the combustion layer will become wider with temperature because the selectivity of the nickel anode goes down, which will result in a loss of power output. One example in case is Hibino's earlier study of SCFC (21-23), in which the furnace temperature is $950^{\circ} \mathrm{C}$ and the fuel cell temperature should be well above $1000^{\circ} \mathrm{C}$. The low power output should be partly accounted for by the combustion layer under such high temperatures.

Besides the single-chamber case, we also investigated the dual-chamber SOFC in a button cell configuration (Fig. 3) with 5\% addition of oxygen in the methane fuel stream in the anode chamber at $800^{\circ} \mathrm{C}$. Although the Deutschmann mechanism is not designed to predict coking, this study will certainly bring more insights into the role that oxygen 


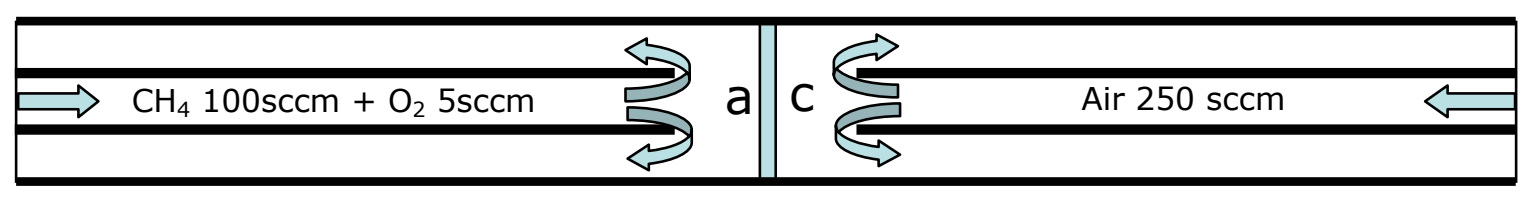

Figure 3. The dual-chamber SOFC simulated in a button cell configuration
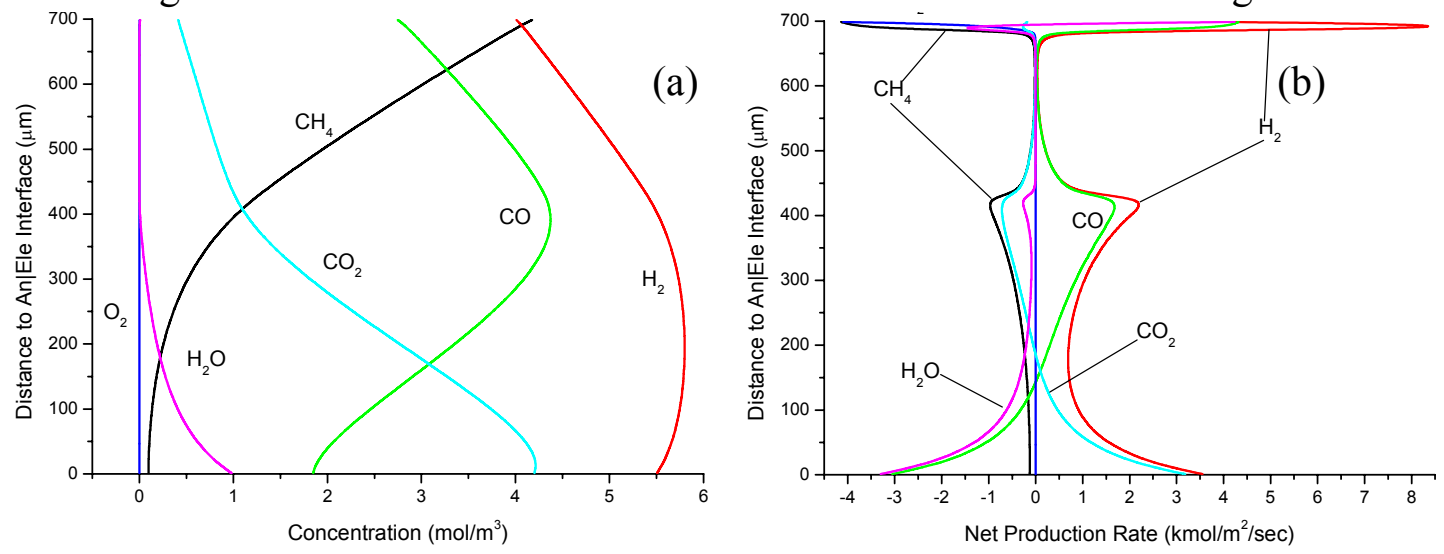

Figure 4. Concentrations and net production rates of gas-phase species in a dualchamber SOFC anode

plays in preventing coking. The cathode chamber is supplied with air at a flow rate of 250 sccm. Load potential is $0.5 \mathrm{~V}$, and all other parameters are the same as the singlechamber case. Fig. 4 shows the species profile and net production rates along the centerline in the button cell. In this case, the anode structure is more complicated than the single-chamber case. One major difference is that there is no combustion layer. Starting from the anode-gas interface, there is a very thin layer of $\sim 5 \mu \mathrm{m}$ in which methane is partially oxidized by ambient $\mathrm{O}_{2}$ to syngas and water, and the heat release is positive. This process quickly depletes most of the oxygen entering the anode, and the water and $\mathrm{CO}_{2}$ produced by this oxidation enables reforming of the methane to occur in the next $15 \mu \mathrm{m}$ or so. The water production rate changes from positive to negative, and the $\mathrm{CO}_{2}$ rate is also negative, while $\mathrm{H}_{2}$ and $\mathrm{CO}$ are being produced. In this region, the heat release is negative. From $650 \mu \mathrm{m}$ to $450 \mu \mathrm{m}$, no significant reaction happens because $\mathrm{H}_{2} \mathrm{O}$ generated by the partial oxidation is consumed. From $450 \mu \mathrm{m}$ to $400 \mu \mathrm{m}, \mathrm{CH}_{4}$ and $\mathrm{CO}_{2}$ start to be consumed again and syngas is produced, but the concentration of $\mathrm{H}_{2} \mathrm{O}$ is still close to zero in this region. Therefore the reaction is "dry" reforming. The layer between $400 \mu \mathrm{m}$ and $100 \mu \mathrm{m}$ is a regular reforming region, in which $\mathrm{H}_{2} \mathrm{O}$ produced by electrochemistry converts $\mathrm{CH}_{4}$ to syngas. Finally, in the last $100 \mu \mathrm{m}$ before the electrolyte, methane is almost depleted, and the dominant chemistry is water-gas shift, with the steam coming from the electrolyte and the $\mathrm{CO}$ coming from the dry-reforming and regular reforming layers above.

Compared with the case with no oxygen addition, the presence of oxygen generates heat and steam within the $20 \mu \mathrm{m}$ layer beneath the anode-gas interface. The increase of cell temperature due to the heat release and the steam reforming of methane are both beneficial to prevent coking. Also, the power output is not influenced because the amount of oxygen is too small. We find that $10 \%$ oxygen (by volume) is needed to reduce the power output by $1 \%$, thus validating the conclusions of zhan et al. (3). 


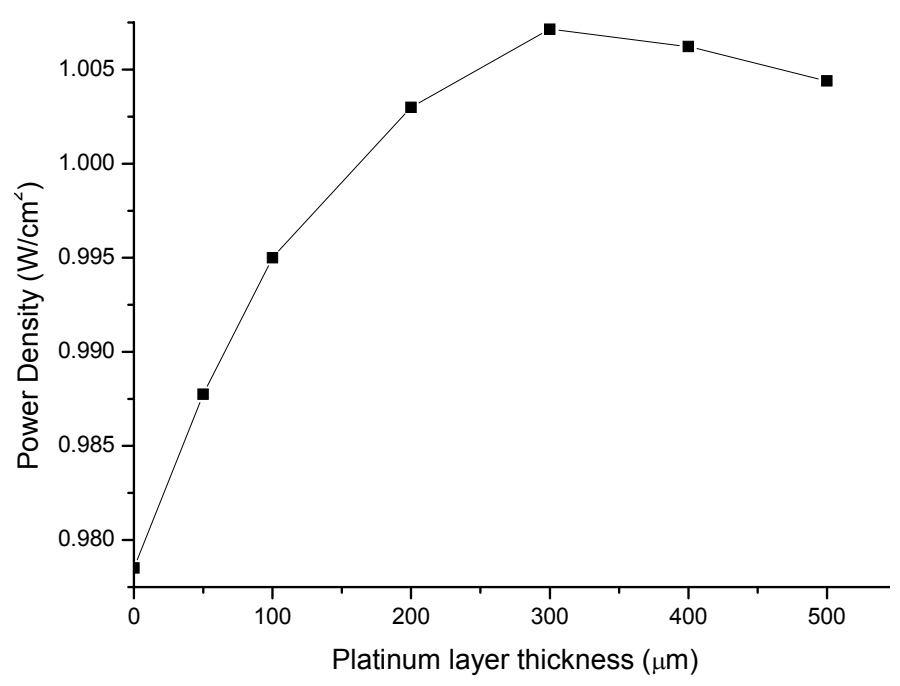

Figure 5. Maximum power density of a single-chamber SOFC with Ni-Pt composite anode versus Pt layer thickness

For the purpose of improving SOFC performance or reduce coking, some groups suggested the possibility of a composite anode and positive results were reported $(3,24)$. Correspondingly, our latest model is capable of simulating a multi-layer anode, each layer with different microstructures and metal catalyst, and with computation mesh automatically refined. Here we simulate an SCFC with the anode composed of two different layers of metal at $750^{\circ} \mathrm{C}$. The thicknesses of both layers changes, with the total thickness fixed at $700 \mu \mathrm{m}$. Combinations among $\mathrm{Ni}, \mathrm{Rh}$ and $\mathrm{Pt}$ are attempted, and most cases deliver worse performance than the monolayer nickel anode of $700 \mu \mathrm{m}$. However, the composite anode with platinum on the gas side and nickel on the electrolyte side is slightly better, as shown in Fig. 5. The highest power is 3\% higher than the monolayer anode case, and the corresponding platinum layer thickness is $300 \mu \mathrm{m}$. The possible reason is that platinum is a better catalyst for syngas combustion than it is for $\mathrm{CH}_{4}$ combustion and it is not a good catalyst for $\mathrm{CH}_{4}$ reforming, so that more $\mathrm{CH}_{4}$ is saved in the combustion layer for the production of $\mathrm{H}_{2}$ in the nickel layer for electrochemistry. This topic will be discussed in more detail in a future paper.

\section{Conclusions}

Through simulation of an SOFC anode with oxygen addition, we find that three distinct regions exist, which starting from the anode-gas interface, are a thin outer layer in which oxygen is nearly fully consumed in oxidizing methane and hydrogen, followed by a reforming region, and then a water-gas shift region deep within the anode. Our results indicate that partial oxidation of methane is unlikely to be the major contributor to either sygnas production or cell heating. Rather, the hydrogen for electrochemistry is mostly produced by internal reforming even in the presence of abundant oxygen (i.e. the singlechamber cases), and cannot be explained by a simple, global partial oxidation reaction. The heat effect is mainly due to the full rather than partial oxidation of both syngas and methane even under fuel-rich conditions. Based on these understanding, we also explored the possibility of a composite anode with different layers of metal catalysts and a $\mathrm{Ni}-\mathrm{Pt}$ composite anode is found to deliver a better performance than a monolayer Ni anode. 


\section{Acknowledgments}

This work was partly supported by the Defense Advanced Research Projects Agency (DARPA) under grant N66001-01-1-8966 and partly by the Office of Naval Research under grant N00014-05-1-0339. We greatly appreciate the constructive suggestions from S. M. Haile, Z. Shao, C. Pantano, W. Lai and J. Mederos.

\section{References}

1. A. Atkinson, S. Barnett, R. J. Gorte, J. T. S. Irvine, A. J. McEvoy, M. Mogensen, S. C. Singhal and J. Vohs, Nature Materials, 3, 17 (2004).

2. R. J. Kee, H. Y. Zhu D. G. Goodwin, Proc. Combustion Institute, 30, 2379 (2005).

3. Z. L. Zhan and S. A. Barnett, Science, 308, 844 (2005).

4. W. Z. Zhu and S. C. Deevi, Mater. Sci. Eng. A-Struct. Mater. Prop. Microstruct. Process., 362, 228 (2003).

5. T. Ishihara and Y. Takita, Catal. Surv. Jpn., 4, 125 (2000).

6. Z. P. Shao, S. M. Haile, J. Ahn, P. D. Ronney, Z. L. Zhan and S. A. Barnett, Nature, 435, 795 (2005).

7. Y. Hao and D. G. Goodwin, J. Electrochem. Soc., 154, B207 (2007).

8. K M. Walters, A.M. Dean, H.Y. Zhu R. J.Kee, J. Power Sources, 123, 182 (2003).

9. X. Jacques-Bedard, T. W. Napporn, R. Roberge and M. Meunier, J. Power Sources, 153, 108 (2006).

10. E. P. Murray, S. J. Harris, J. Liu and S. A. Barnett, Electrochem. Solid State Letters, 9, A292 (2006).

11. T. Hibino, A. Hashimoto, M. Yano, M. Suzuki, S. Yoshida and M. Sano, J. Electrochem. Soc., 149, A133 (2002).

12. A. M. DeGroote and G. F. Froment, Applied Catalysis a-General, 138, 245 (1996).

13. O. Deutschmann and L. D. Schmidt, AIChE J., 44, 2465 (1998).

14. H. Y. Zhu, R. J. Kee, V. M. Janardhanan, O. Deutschmann and D. G. Goodwin, J. Electrochem. Soc., 152, A2427 (2005).

15. E. S. Hecht, G. K. Gupta, H. Y. Zhu, A. M. Dean, R. J. Kee, L. Maier and O. Deutschmann, Applied Catalysis a-General, 295, 40 (2005).

16. Y. Hao, Z. P. Shao, J. Mederos, W. Lai, D. G. Goodwin and S. M. Haile, Solid State Ionics (2006).

17. W. Kim, A. V. Virkar, K. Z. Fung, K. Mehta and S. C. Singhal, J. Electrochem. Soc., 146, 69 (1999).

18. T. Hibino, A. Hashimoto, T. Inoue, J. Tokuno, S. Yoshida and M. Sano, J. Electrochem. Soc., 148, A544 (2001).

19. T. Suzuki, P. Jasinski, V. Petrovsky, H. U. Anderson and F. Dogan, J. Electrochem. Soc., 151, A1473 (2004).

20. T. W. Napporn, X. Jacques-Bedard, F. Morin and M. Meunier, J. Electrochem. Soc., 151, A2088 (2004).

21. T. Hibino, S. Q. Wang, S. Kakimoto and M. Sano, Solid State Ionics, 127, 89 (2000).

22. T. Hibino, H. Tsunekawa, S. Tanimoto and M. Sano, J. Electrochem. Soc., 147, 1338 (2000).

23. T. Hibino, A. Hashimoto, T. Inoue, J. Tokuno, S. Yoshida and M. Sano, J. Electrochem. Soc., 147, 2888 (2000).

24. A. V. Virkar, J. Chen, C. W. Tanner J.W. Kim, Solid State Ionics, 131, 189 (2000). 